\title{
Transport of carnitine and acetylcarnitine by carnitine/organic cation transporter (OCTN) 2 and OCTN3 into epididymal spermatozoa
}

\author{
Daisuke Kobayashi, Ikumi Tamai ${ }^{1}$, Yoshimichi Sai, Kazuhiro Yoshida, Tomohiko Wakayama ${ }^{2}$, \\ Yasuto Kido, Jun-ichi Nezu ${ }^{3}$, Shoichi Iseki ${ }^{2}$ and Akira Tsuji \\ Division of Pharmaceutical Sciences, Department of Molecular Biopharmaceutics, Graduate School of Natural \\ Science and Technology, Kanazawa University, Kakuma-machi, Kanazawa 920-1192, Japan, ${ }^{1}$ Faculty of \\ Pharmaceutical Sciences, Tokyo University of Science, 2641 Yamasaki, Noda, Chiba 278-8510, Japan, ${ }^{2}$ Department \\ of Histology and Embryology, Graduate School of Medical Science, Kanazawa University, Takara-machi, Kanazawa \\ 920-8640, Japan and ${ }^{3}$ Chugai Pharmaceutical Co. Ltd, Shizuoka, Japan
}

Correspondence should be addressed to A Tsuji; Email: tsuji@kenroku.kanazawa-u.ac.jp

\begin{abstract}
Carnitine and acetylcarnitine are important for the acquisition of motility and maturation of spermatozoa in the epididymis. In this study, we examined the involvement of carnitine/organic cation transporter (OCTN) in carnitine and acetylcarnitine transport in epididymal spermatozoa of mice. Uptake of both compounds by epididymal spermatozoa was time-dependent and partially $\mathrm{Na}^{+}$-dependent. Kinetic analyses revealed the presence of a high-affinity transport system in the spermatozoa, with $K_{\mathrm{m}}$ values of 23.6 and $6.57 \mu \mathrm{M}$ for carnitine and acetylcarnitine respectively in the presence of $\mathrm{Na}^{+}$. Expression of OCTN2 and OCTN3 in epididymal spermatozoa was confirmed by immunofluorescence analysis. The involvement of these two transporters in carnitine and acetylcarnitine transport was supported by a selective inhibition study. We conclude that both $\mathrm{Na}^{+}$-dependent and -independent carnitine transporters, OCTN2 and OCTN3, mediate the supply of carnitine and acetylcarnitine to epididymal spermatozoa in mice.

Reproduction (2007) 134 651-658
\end{abstract}

\section{Introduction}

Acquisition of motility and maturation of spermatozoa occur during passage through the epididymal tract (Dacheux \& Paquingnon 1980, Jeulin \& Lewin 1996). Carnitine and acetylcarnitine are essential nutrients for sperm maturation (Casillas \& Chaipayungpan 1979, Hinton et al. 1981) and are present in epididymal plasma at concentrations of 1-63 mM (Marquis \& Fritz 1965, Casillas 1972, Hinton et al. 1979, Jeulin \& Lewin 1996), which is significantly higher than that in blood plasma (about $50 \mu \mathrm{M}$ ). Such high concentrations of carnitine and acetylcarnitine in epididymal plasma may be due to active supply from blood to the tissue, and indeed, the presence of transporters in the tissue has been reported (Yeung et al. 1980, Cooper et al. 1986, Radigue et al. 1996, Kobayashi et al. 2005). The concentration of carnitine in epididymal plasma increases from the proximal part (caput) to the distal part (cauda) of the epididymis (Hinton et al. 1979, Casillas et al. 1984, Jeulin et al. 1987, Jeulin \& Lewin 1996). Similarly, the carnitine concentration in epididymal spermatozoa increases during transition through the epididymal tract (Casillas 1973, Casillas \& Chaipayungpan 1979, Casillas et al.
1984). Sperm motility is correlated with acetylcarnitine concentration in ejaculated human spermatozoa (Johansen \& Bohmer 1979). These observations suggest that the concentrations of carnitine and acetylcarnitine in spermatozoa are critical for the acquisition of sperm motility. Active transport across the plasma membrane of spermatozoa would be essential, since carnitine and acetylcarnitine are zwitterionic and highly hydrophilic. Temperature-dependent transport of carnitine in ejaculated bovine spermatozoa (Deana et al. 1989) and saturable carnitine transport in bovine caput epididymal spermatozoa (Casillas 1973) and human ejaculated spermatozoa (Xuan et al. 2003) has been reported. Nevertheless, other authors have suggested that carnitine uptake occurs through passive diffusion into spermatozoa in the bovine cauda epididymides (Casillas 1973) and epididymides of the boar (Jeulin et al. 1994).

We and others have isolated carnitine/organic cation transporters (OCTNs) in humans, rats, and mice (Tamai et al. 1997, 1998, 2000, Wu et al. 1998, 1999, 2000, Nezu et al. 1999). The first member of OCTNs, OCTN1 (solute carrier (SLC)22A4), transports cationic xenobiotics, such as tetraethylammonium (Tamai et al. 
1997, 2000, 2004, Yabuuchi et al. 1999) and ergothioneine (Grundemann et al. 2005), and has a low activity for carnitine transport (Yabuuchi et al. 1999, Tamai et al. 2000, Grundemann et al. 2005). OCTN2 (SLC22A5) is an $\mathrm{Na}^{+}$-dependent, high-affinity $\left(K_{\mathrm{m}}=4-25 \mu \mathrm{M}\right)$ carnitine transporter (Tamai et al. 1998, 2000, Sekine et al. 1998, Wu et al. 1999). Human carnitine transporter CT2 (SLC22A16) and mouse OCTN3 (SLC22A21) transport carnitine with high affinity $\left(K_{\mathrm{m}}=20\right.$ and $3 \mu \mathrm{M}$ respectively) in a sodium-independent manner ( $\mathrm{Nezu}$ et al. 1999, Ohashi et al. 1999, Tamai et al. 2000, Enomoto et al. 2002). On the other hand, Nakanishi et al. (2001) reported that the $\mathrm{Na}^{+}$- and $\mathrm{Cl}^{-}$-coupled neutral and cationic amino acid transporter $\mathrm{ATB}^{0,+}$ (SLC6A14) can transport carnitine with low affinity $\left(K_{\mathrm{m}}=0.83 \mathrm{mM}\right)$. Furthermore, OCTN2-deficient JVS mice showed male infertility with epididymal dysfunction (Toshimori et al. 1999), and OCTN3 is selectively expressed in the male reproductive tissue of mice (Tamai et al. 2000). Xuan et al. (2003) reported the presence of proteins that react with antibodies against mouse OCTN1, OCTN2 and OCTN3 in human ejaculated spermatozoa. Based on these findings, we considered that OCTN2 and OCTN3 could contribute to carnitine and acetylcarnitine transport in epididymal spermatozoa. However, this issue remains to be clarified at the molecular level.

In this study, we examined the localization and involvement of the carnitine transporters OCTN2 and OCTN3 in the supply of carnitine and acetylcarnitine to murine spermatozoa.

\section{Results}

Time courses and ion dependence of $\left[{ }^{3} \mathrm{H}\right]$ carnitine and $\left.{ }^{3} \mathrm{H}\right]$ acetylcarnitine uptake by epididymal spermatozoa of mice

The uptakes of $\left[{ }^{3} \mathrm{H}\right]$ carnitine and $\left[{ }^{3} \mathrm{H}\right]$ acetylcarnitine by epididymal spermatozoa were measured over 30 min. Figure 1 shows that the uptake increased linearly for 5 min in both the presence and the absence of $\mathrm{Na}^{+}$, but was slightly lower in its absence (extracellular $\mathrm{Na}^{+}$was replaced with $\mathrm{N}$-methylglucamine; Fig. 1). Since the steady-state uptake amounts of both the compounds (Fig. 1) were higher than the intracellular water space (3.44 $\mu \mathrm{l} / \mathrm{mg}$ protein), estimated as the difference between the uptakes of $\left[{ }^{3} \mathrm{H}\right]$ water and $\left[{ }^{14} \mathrm{C}\right]$ inulin, in epididymal spermatozoa, carnitine, and acetylcarnitine seem to be accumulated in the intracellular space of epididymal spermatozoa, suggesting the involvement of active transport. In addition, uptake clearance of acetylcarnitine was higher than that of carnitine into spermatozoa (Fig. 1). Therefore, acetylcarnitine was used as substrate in the following study of ion-dependent and inhibitory effects. Table 1 shows the sodium ion dependence of the uptake of $\left[{ }^{3} \mathrm{H}\right]$ acetylcarnitine. When $\mathrm{Na}^{+}$was replaced with lithium or potassium, the uptake of $\left[{ }^{3} \mathrm{H}\right]$ acetylcarnitine
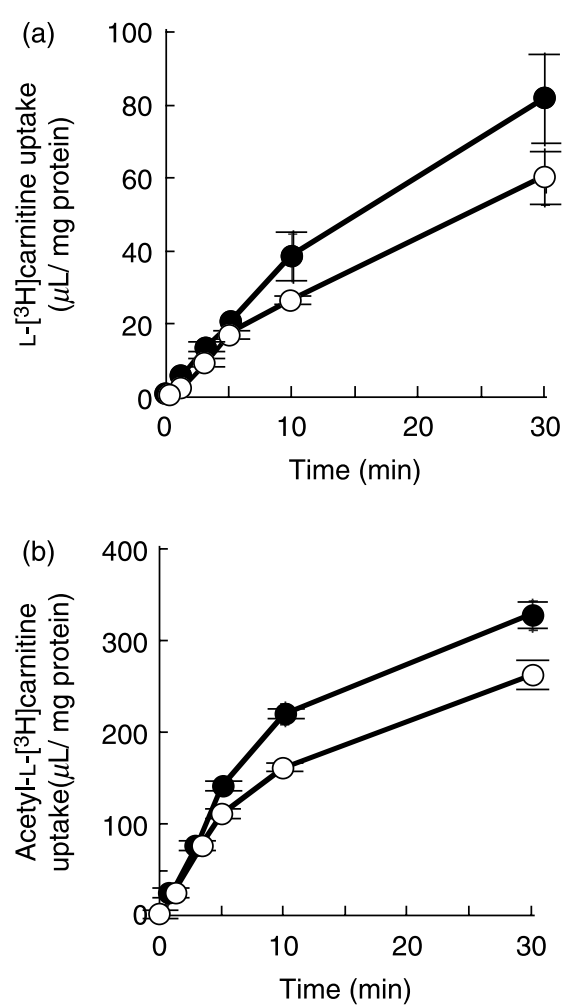

Figure 1 Time course of uptake of (a) $\left[{ }^{3} \mathrm{H}\right]$ carnitine and (b) $\left[{ }^{3} \mathrm{H}\right]$ acetylcarnitine uptake by murine spermatozoa. The uptakes of

(a) L- $\left[{ }^{3} \mathrm{H}\right]$ carnitine $(12 \mathrm{nM})$ and (b) $\left[{ }^{3} \mathrm{H}\right]$ acetyl-L-carnitine $(12.5 \mathrm{nM})$ by spermatozoa were measured at $37^{\circ} \mathrm{C}$ in transport buffer $(\mathrm{pH} 7.4)$ in the presence (closed circle) or the absence (open circle) of $\mathrm{Na}^{+}$. $\mathrm{Na}^{+}$was replaced with $\mathrm{NMG}^{+}$. The results are shown as mean \pm s.E.M. of three determinations.

Table 1 Effects of inorganic cations and anions on $\left[{ }^{3} \mathrm{H}\right]$ acetylcarnitine uptake by spermatozoa.

\begin{tabular}{lc}
\hline Cations/anions & Relative uptake $(\%$ of control) \\
\hline Cations & \\
Sodium (control) & $100 \pm 2$ \\
Lithium & $139 \pm 3^{*}$ \\
Potassium & $117 \pm 4^{*}$ \\
N-Methylglucamine & $85 \pm 4^{*}$ \\
Choline & $48 \pm 2^{*}$ \\
Anions & $100 \pm 2$ \\
Chloride (control) & $111 \pm 2^{*}$ \\
Thiocyanate & $111 \pm 2^{*}$ \\
Nitrate & $121 \pm 3^{*}$ \\
Gluconate & $52 \pm 2^{*}$ \\
Sulfate & \\
\hline
\end{tabular}

The uptake of $\left[{ }^{3} \mathrm{H}\right]$ acetyl-L-carnitine $(12.5 \mathrm{nM})$ by spermatozoa was measured for $3 \mathrm{~min}$ at $37^{\circ} \mathrm{C}$. When sodium or chloride ions were replaced with other cations or anions, chloride or sodium ions were used as counter-ions respectively. The result is shown as a percentage of the uptake in the presence of sodium chloride. Each value represents the mean \pm S.E.M. of four determinations. *Significantly different from the control uptake (sodium chloride buffer) by one-way ANOVA with Tukey-Kramer's post hoc test $(P<0.05)$. 
was increased, whereas it was decreased when $\mathrm{Na}^{+}$ was replaced with choline or $\mathrm{N}$-methylglucamine. These results suggested that both $\mathrm{Na}^{+}$-dependent and -independent transporters exist in murine spermatozoa. The effects of changing from chloride ion to other anions were also examined. Thiocyanate, nitrate, and gluconate slightly increased the uptake of $\left[{ }^{3} \mathrm{H}\right]$ acetylcarnitine, while replacement with sulfate ion decreased the uptake.

\section{Concentration dependence of carnitine and acetylcarnitine uptake by murine spermatozoa}

The concentration dependence of the uptake of carnitine by murine spermatozoa is shown in Fig. $2 \mathrm{a}$, and that in the case of acetylcarnitine is shown in Fig. 2b. Both uptakes were saturable. Eadie-Hofstee plots indicated the involvement of a single saturable transport system in each case (Fig. 2c and d). The kinetic parameters for carnitine uptake were calculated to be $K_{\mathrm{m}}=23.6 \pm$ $14.5 \mu \mathrm{M}, V_{\max }=281 \pm 176 \mathrm{pmol} / \mathrm{mg}$ protein $/ 3 \mathrm{~min}$, and $k_{\mathrm{d}}=6.55 \pm 1.33 \mu \mathrm{L} / \mathrm{mg}$ protein $/ 3 \mathrm{~min}$, and those for acetylcarnitine were $K_{\mathrm{m}}=6.57 \pm 1.77 \mu \mathrm{M}, \quad V_{\max }=$ $390 \pm 96 \mathrm{pmol} / \mathrm{mg}$ protein $/ 3 \mathrm{~min}$, and $k_{\mathrm{d}}=7.99 \pm$ $2.63 \mu \mathrm{L} / \mathrm{mg}$ protein $/ 3 \mathrm{~min}$ (means \pm S.E.M.). These results (a)

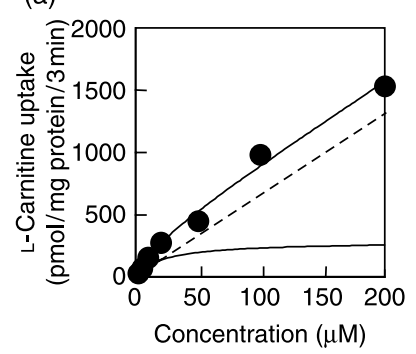

(c)

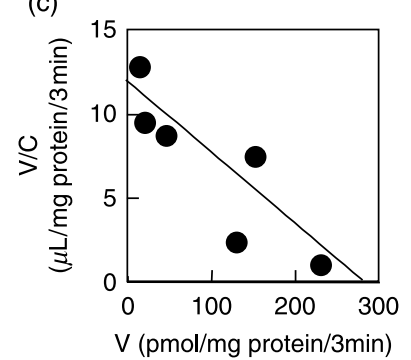

(b)

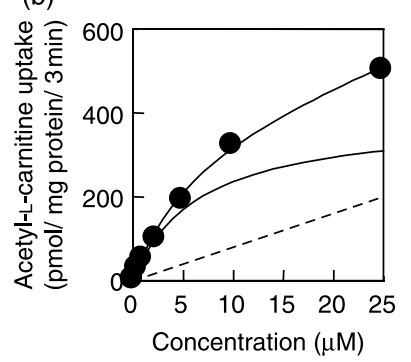

(d)

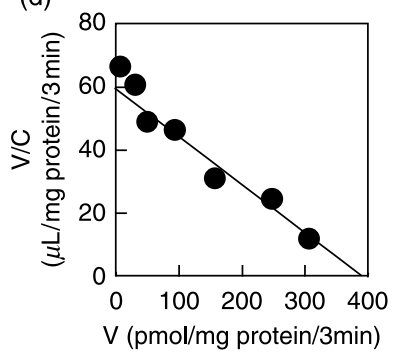

Figure 2 Concentration dependence of uptake of (a and c) carnitine and ( $b$ and $d$ ) acetylcarnitine by murine spermatozoa. The uptake of (a) L-carnitine and (b) acetyl-L-carnitine by spermatozoa at various concentrations of carnitine or acety-L-carnitine was measured at $37^{\circ} \mathrm{C}$ in transport buffer $\left(\mathrm{pH} \mathrm{7.4)}\right.$ in the presence of $\mathrm{Na}^{+}$. The amounts of total, saturable, and non-saturable transport, estimated from the kinetics parameters as described in the Results, are represented by the upper solid, lower solid, and dotted lines (a and b). Eadie-Hofstee plots for (c) L-carnitine and (d) acetyl-L-carnitine are shown after subtracting the non-saturable uptake, estimated from the slope of the line through the two points at higher concentration in (a) or (b). Each result represents the mean and S.E.M. $(n=3$ or 4$)$. suggested that spermatozoa in mice have a relatively high-affinity carnitine transporter.

\section{Inhibitory effects of several compounds on $\left[{ }^{3} \mathrm{H}\right]$ acetylcarnitine uptake by murine spermatozoa}

To characterize the uptake systems for acetylcarnitine in spermatozoa, we measured $\left[{ }^{3} \mathrm{H}\right]$ acetylcarnitine uptake in the presence of several compounds. Table 2 shows that $50 \mu \mathrm{M} \gamma$-butyrobetaine and $500 \mu \mathrm{M}$ verapamil inhibited the uptake to $<50 \%$ of that in the absence of inhibitor. L-Carnitine, D-carnitine, glycinebetaine, quinidine, and tetraethylammonium (TEA) also significantly reduced $\left[{ }^{3} \mathrm{H}\right]$ acetylcarnitine uptake by spermatozoa. Spermine, spermidine, and arginine were not inhibitory.

\section{Expression of OCTNs in epididymal spermatozoa of mice}

To identify the sodium-dependent and -independent carnitine transporters that showed high affinity for carnitine and acetylcarnitine at the molecular level, we employed immunofluorescence analysis, using antibodies against OCTN transporters. As shown in Fig. 3, strong signals (red) were observed in the tail of epididymal spermatozoa with anti-OCTN2 and -OCTN3 antibodies, and weak signals were observed with antiOCTN1 antibody. No signals were detected with control IgG (Fig. 4c). A strong expression of OCTN3 was observed especially in corpus and cauda epididymidal spermatozoa. The ratio of OCTN3-positive spermatozoa

Table 2 Inhibitory effects of several endogenous compounds and xenobiotics on $\left[{ }^{3} \mathrm{H}\right]$ acetylcarnitine uptake by spermatozoa.

\begin{tabular}{lrc}
\hline Inhibitors & Concentration $(\mu \mathrm{M})$ & $\begin{array}{c}\text { Relative uptake } \\
(\% \text { of control })\end{array}$ \\
\hline No inhibitors (control) & & 100 \\
Endogenous compounds & 5 & $77 \pm 2^{*}$ \\
L-Carnitine & 50 & $61 \pm 1^{*}$ \\
L-Carnitine & 5 & $88 \pm 2^{*}$ \\
$\gamma$-Butyrobetaine & 50 & $44 \pm 1^{*}$ \\
$\gamma$-Butyrobetaine & 500 & $113 \pm 2$ \\
Glycinebetaine & 5000 & $74 \pm 2^{*}$ \\
Glycinebetaine & 5000 & $111 \pm 3$ \\
Spermine & 5000 & $96 \pm 4$ \\
Spermidine & 5000 & $135 \pm 2$ \\
Arginine & & $89 \pm 2$ \\
Xenobiotics & 5 & $79 \pm 1^{*}$ \\
D-Carnitine & 50 & $115 \pm 3$ \\
D-Carnitine & 50 & $68 \pm 2^{*}$ \\
Quinidine & 500 & $69 \pm 4^{*}$ \\
Quinidine & 50 & $36 \pm 2^{*}$ \\
Verapamil & 500 & $78 \pm 1^{*}$ \\
Verapamil & 5000 & \\
TEA & & \\
\hline
\end{tabular}

The uptake of $\left[{ }^{3} \mathrm{H}\right]$ acetyl-L-carnitine $(12.5 \mathrm{nM})$ by spermatozoa was measured for $3 \mathrm{~min}$ at $37^{\circ} \mathrm{C}$ in transport buffer ( $\mathrm{pH} 7.4$ ) containing each compound. Each value represents the mean \pm s.E.M. of four determinations. *Significantly decreased from the control uptake by Student's $t$-test one-way ANOVA with Tukey-Kramer's post hoc test $(P<0.05)$. 


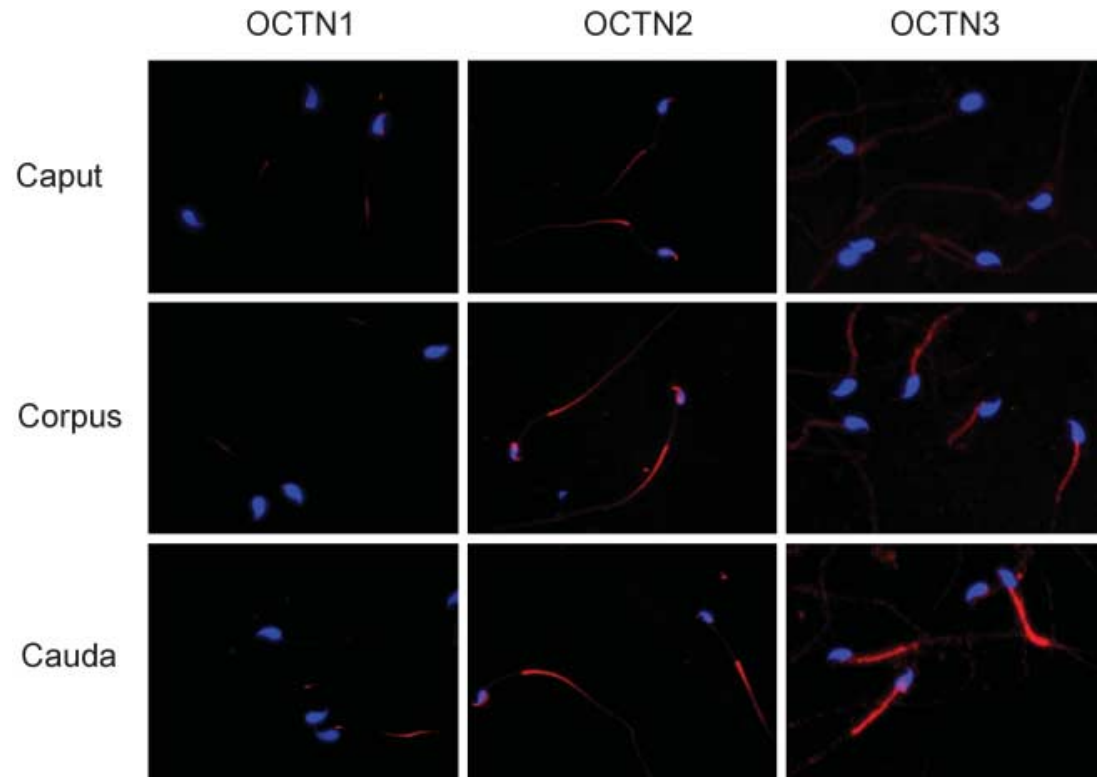

Figure 3 Expression of OCTN proteins in murine epididymal spermatozoa. Spermatozoa isolated from caput, corpus, and cauda epididymides were incubated with affinity-purified antiserum against mouse OCTN1, OCTN2, or OCTN3 and examined by immunofluorescence microscopy. The OCTN proteins appear in red and nuclei in blue. was significantly higher in corpus $(92.8 \pm 2.2 \%, n=6)$ and cauda $(92.7 \pm 1.9 \%, n=6)$ compared with caput $(71.7 \pm 2.4 \%, n=6)$. Figure 4 clearly shows that the localizations of OCTN2 and OCTN3 in spermatozoa were different. OCTN2 was localized to the principal piece of sperm tail, whereas OCTN3 was localized to the middle piece of the sperm tail, which lies adjacent to the nucleus (blue).

\section{Regional difference of acetylcarnitine uptake into epididymal spermatozoa of mice}

The transport activity of acetylcarnitine was measured in caput, corpus, and cauda spermatozoa (Fig. 5). The acetylcarnitine transport activity was extremely high in corpus spermatozoa in the absence of $\mathrm{Na}^{+}$as well as in the presence of $\mathrm{Na}^{+}$.

\section{Comparison of the inhibitory effects of several compounds on $\left.{ }^{3} \mathrm{H}\right]$ carnitine uptake by OCTN2, OCTN3, and epididymal spermatozoa of mice}

To clarify the functional involvement of OCTN2 and OCTN3 in carnitine transport in epididymal spermatozoa, detailed inhibition studies were conducted. First, we required specific inhibitors for OCTN2 or OCTN3 to differentiate OCTN2- and OCTN3-mediated transports. The $I C_{50}$ values of six compounds ( $\gamma$-butyrobetaine, butyryl-L-carnitine, pyrilamine, quinidine, TEA, and verapamil) were obtained and compared. As shown in Table 3, the $\mathrm{IC}_{50}$ values of pyrilamine for OCTN2- or OCTN3-mediated cartnitine uptake were 41.7 and $318 \mu \mathrm{M}$ respectively, suggesting that pyrilamine has a higher affinity for OCTN2. In contrast, $\gamma$-butyrobetaine and butyryl-L-carnitine showed a higher affinity for OCTN3 than for OCTN2. The $\mathrm{IC}_{50}$ values for OCTN2 and OCTN3 were comparable in the cases of quinidine, TEA, and verapamil. Based on these results, we chose pyrilamine and $\gamma$-butyrobetaine as specific (or more strictly, preferential) inhibitors of OCTN2 and OCTN3 respectively. The $\mathrm{IC}_{50}$ values of pyrilamine and $\gamma$-butyrobetaine for carnitine uptake in epididymal spermatozoa were 208 and $30.7 \mu \mathrm{M}$ respectively. These results suggest that both OCTN2 and OCTN3 contribute to carnitine uptake in epididymal spermatozoa.
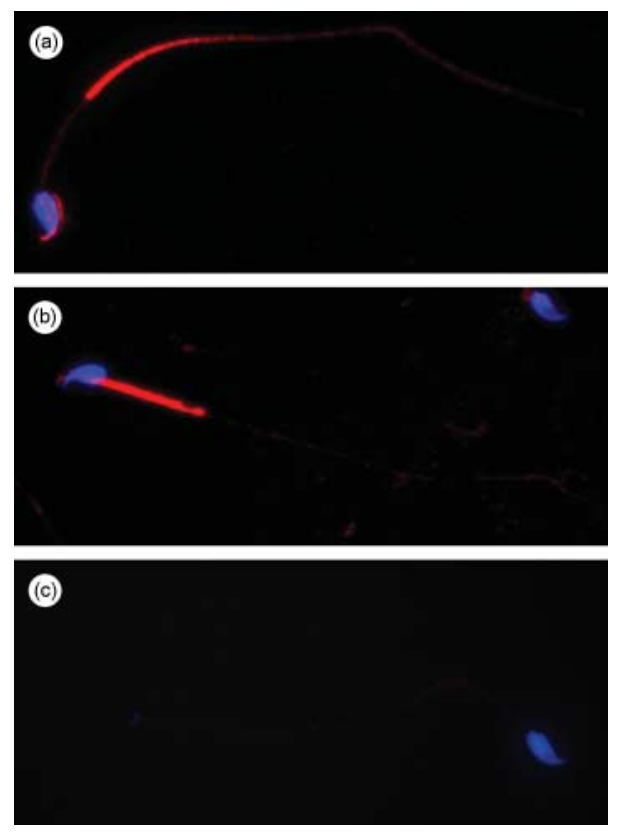

Figure 4 Expressions of OCTN2 and OCTN3 proteins in epididymal spermatozoa in mice. Spermatozoa isolated from cauda epididymis were incubated with affinity-purified antiserum against mouse (a) OCTN2, (b) OCTN3, or (c) normal IgG. The OCTNs appear in red and nuclei in blue. 


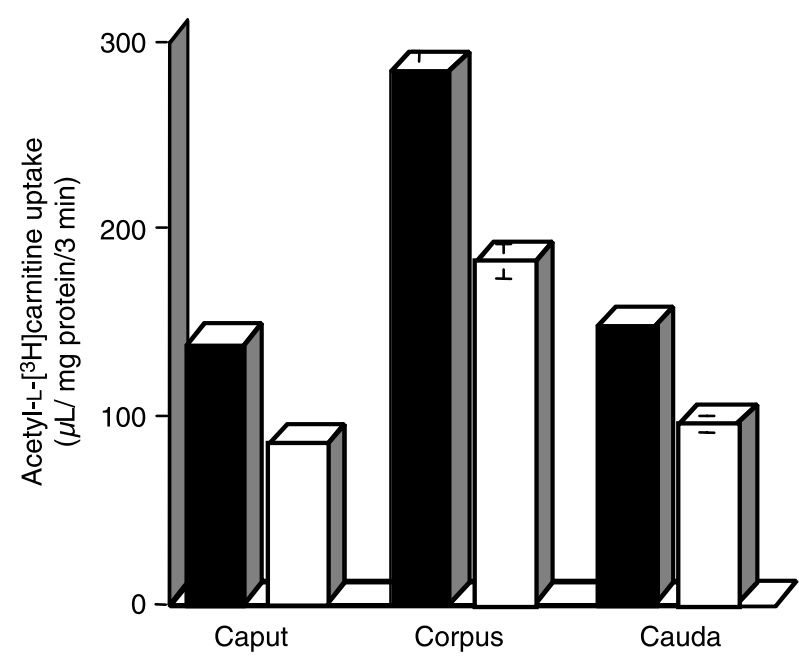

Figure 5 Regional difference of uptake of $\left[{ }^{3} \mathrm{H}\right]$ acety-L-carnitine by murine epididymal spermatozoa. The uptake of $\left[{ }^{3} \mathrm{H}\right]$ acetyl-L-carnitine $(12.5 \mathrm{nM})$ by spermatozoa was measured at $37^{\circ} \mathrm{C}$ in transport buffer $(\mathrm{pH} 7.4)$ in the presence (closed column) or the absence (open column) of $\mathrm{Na}^{+}$. $\mathrm{Na}^{+}$was replaced with $\mathrm{NMG}^{+}$. The results are shown as mean \pm s.E.M. of four determinations.

\section{Discussion}

In this study, characterization and molecular identification of transporters involved in the uptake of carnitine and acetylcarnitine in epididymal spermatozoa were examined, focusing on OCTN transporters. Although it was reported that uptake of carnitine in spermatozoa could be explained by simple diffusion (Jeulin et al. 1994), we demonstrated the presence of a saturable transport system for carnitine in epididymal spermatozoa. This transport activity was reduced by carnitine analogs and cationic compounds. The apparent discrepancy may reflect species difference (boar and mouse) and the different uptake times used; Jeulin et al. (1994) measured at steady state (10 or $20 \mathrm{~min}$ ) and in the present study uptake was measured for $3 \mathrm{~min}$.

Table $3 \mathrm{IC}_{50}$ values of various compounds for the uptake of $\left[{ }^{3} \mathrm{H}\right]$ carnitine by mouse carnitine/organic cation transporter (OCTN) 2, OCTN3, and spermatozoa of mice.

\begin{tabular}{lccc}
\hline & \multicolumn{3}{c}{ IC $_{\mathbf{5 0}}(\mu \mathrm{M})$} \\
\cline { 2 - 4 } Inhibitors & OCTN2 & OCTN3 & Spermatozoa \\
\hline -Butyrobetaine & 167 & 1.73 & 30.7 \\
Butyryl-L-carnitine & 7.32 & 1.06 & ND \\
Pyrilamine & 41.7 & 318 & 208 \\
Quinidine & 239 & 142 & ND \\
TEA & 132 & 392 & ND \\
Verapamil & 58.8 & 20.2 & ND
\end{tabular}

The uptake of L- $\left[{ }^{3} \mathrm{H}\right]$ carnitine by mouse OCTN2 or OCTN3 expressed in HEK293 cells or spermatozoa was measured for $3 \mathrm{~min}$ at $37^{\circ} \mathrm{C}$ in transport buffer $(\mathrm{pH} 7.4)$ in the presence of various concentrations of each inhibitor. The $\mathrm{IC}_{50}$ value of each compound was estimated from the inhibition of OCTN2- or OCTN3-mediated uptake after subtracting the uptake by mock from that by OCTN2- or OCTN3-expressing HEK293 cells using the MULTI program. ND, not determined.
We observed both $\mathrm{Na}^{+}$-dependent and -independent transport of carnitine and acetylcarnitine. Eadie-Hofstee plot analysis indicated a single saturable component with $K_{\mathrm{m}}$ values of $23.6 \mu \mathrm{M}$ for carnitine and $6.57 \mu \mathrm{M}$ for acetylcarnitine in epididymal spermatozoa. Furthermore, expression of the high-affinity carnitine transporters OCTN2 and OCTN3, which are $\mathrm{Na}^{+}$-dependent and -independent respectively (Tamai et al. 2000), was confirmed in epididymal spermatozoa. These results suggested that OCTN2 and OCTN3 are implicated in the $\mathrm{Na}^{+}$-dependent and -independent transport of both carnitine and acetylcarnitine, even though kinetic analysis suggested a single saturable mechanism. This apparent discrepancy can be explained by the fact that kinetic analysis could not distinguish between $\mathrm{Na}^{+}$dependent and -independent transporters, since the affinities of these two transporters for carnitine or acetylcarnitine are not sufficiently different to allow the separation of two saturable components. The involvement of both OCTN2 and OCTN3 in the transport of carnitine and acetylcarnitine was further confirmed by inhibition studies. Concentration-dependent inhibition studies showed that pyrilamine and $\gamma$-butyrobetaine could be used as selective inhibitors for OCTN2 and OCTN3 respectively. The $\mathrm{IC}_{50}$ values of pyrilamine and $\gamma$-butyrobetaine for carnitine uptake in epididymal spermatozoa were 208 and $30.7 \mu \mathrm{M}$ respectively. These values are intermediate between the $\mathrm{IC}_{50}$ values for OCTN2 and OCTN3, supporting the idea that both OCTN2 and OCTN3 are involved in carnitine uptake in epididymal spermatozoa.

Interestingly, the expression of OCTN3, which is localized to the middle piece of the sperm tail, and the ratio of OCTN3-positive spermatozoa were increased during transition though the epididymal tract. Mitochondria, where carnitine is used for fatty acid oxidation, exist at the middle piece of the sperm tail, and it has been reported that the conversion of $\left[{ }^{14} \mathrm{C}\right]$ palmitate to $\left[{ }^{14} \mathrm{C} \mathrm{CO}_{2}\right.$ in bovine epididymal spermatozoa is stimulated by addition of carnitine and acetylcarnitine (Casillas 1972). Acquisition of motility of spermatozoa occurs during passage through the murine epididymal tract (Soler et al. 1994), and carnitine is essential for sperm maturation (Casillas \& Chaipayungpan 1979, Hinton et al. 1981, Jeulin \& Lewin 1996). Accordingly, we suggest that OCTN3 plays a role in fatty acid oxidation and motility of epididymal spermatozoa by supplying carnitine/acetylcarnitine to the spermatozoa. The expression pattern of OCTN2, which is localized to the principal piece of the sperm tail, is different from that of OCTN3. Similarly, glucose transporter (GLUT) 1 is localized to the principal piece, and GLUT3 and GLUT5 to the middle piece of the sperm tail (Angulo et al. 1998). Although the reason for the differential localizations is not clear, OCTN2 and OCTN3 may have distinct roles in carnitine/acetylcarnitine transport in epididymal spermatozoa. 
Spermatozoa were usually obtained from whole epididymides. Since cauda spermatozoa are more motile than caput spermatozoa and most of the spermatozoa were reserved in the cauda, it is likely that most of the spermatozoa from whole epididymides were from cauda epididymis. Therefore, we also examined the transport study by spermatozoa from caput, corpus, and cauda epididymides independently. The results suggested that caput and corpus spermatozoa exhibited both $\mathrm{Na}^{+}$-dependent and -independent transport of carnitine and acetylcarnitine the same as observed in cauda spermatozoa. Although the ratio of the percentage of OCTN3-positive spermatozoa in corpus was similar to that in cauda, the $\mathrm{Na}^{+}$-independent uptake of acetylcarnitine was higher in spermatozoa from the corpus than those in the cauda. This discrepancy may be attributed to other transporters or regional differences of intrinsic carnitine or inorganic ions $\left(\mathrm{Na}^{+}\right.$or $\mathrm{K}^{+}$, etc.) inside and outside of spermatozoa (Levine \& Marsh 1971, Turner et al. 1977, Jenkins et al. 1980, Jeulin \& Lewin 1996).

The expression of OCTN1 was very low in epididymal spermatozoa. Since the carnitine transport activity of OCTN1 is very low when compared with that of OCTN2 and OCTN3 (Tamai et al. 2000), OCTN1 might play a role in the transport of compounds other than carnitine, such as ergothioneine (Grundemann et al. 2005). Involvement of another carnitine transporter, $\mathrm{ATB}^{0,+}$, which shows low affinity for carnitine (Nakanishi et al. 2001), would be negligible under our experimental conditions, since a substrate of $\mathrm{ATB}^{0,+}$, arginine $(5 \mathrm{mM})$, had no inhibitory effect. However, since the carnitine concentration in epididymal plasma is of millimolar order, involvement of $\mathrm{ATB}^{0,+}$ in physiological carnitine transport by spermatozoa cannot be completely excluded.

The human counterpart of mouse OCTN3 has not yet been identified. However, the human carnitine transporter CT2 (SLC22A16) is selectively expressed in male reproductive tissues, such as Sertoli cells, epididymal epithelial cells, and spermatozoa (Enomoto et al. 2002). Although the amino acid sequence homology between mouse OCTN3 and human CT2 is not high (33\%), CT2 may be the physiological functional counterpart of murine OCTN3 in carnitine/acetylcarnitine transport. Mouse SLC22A16 (GenBank Accession Number BC100473) exhibits about 57 and 30\% similarity to human $\mathrm{CT} 2$ and murine OCTN3 respectively. However, the possible involvement of mouse CT2 in carnitine/ acetylcarnitine transport in spermatozoa cannot yet be discussed since the tissue expression profile and transport function of mouse CT2 remain to be established.

This study, the first characterization of carnitine transport in murine spermatozoa, has demonstrated the presence of $\mathrm{Na}^{+}$-dependent and -independent transporters, OCTN2 and OCTN3, in epididymal spermatozoa. In addition, it has clarified that both OCTN2 and OCTN3 are expressed in the sperm tail and that the ratio of OCTN3-positive spermatozoa increases during migration though the epididymal tract. Accordingly, these OCTN transporters are likely to play key roles in supplying carnitine and acetylcarnitine to maintain the fertility of spermatozoa.

\section{Materials and Methods}

\section{Materials}

L-[Methyl- $\left.{ }^{3} \mathrm{H}\right]$ carnitine $\left(\left[{ }^{3} \mathrm{H}\right]\right.$ carnitine, $\left.65 \mathrm{Ci} / \mathrm{mmol}\right)$ was purchased from Amersham Biosciences Corp. Acetyl-L$\left[\mathrm{N}\right.$-methyl- $\left.{ }^{3} \mathrm{H}\right]$ carnitine hydrochloride $\left(\left[{ }^{3} \mathrm{H}\right]\right.$ acetylcarnitine, $80 \mathrm{Ci} / \mathrm{mmol}$ ) was purchased from American Radiolabeled Chemicals Inc. (St Louis, MO, USA). [Methoxy $\left.-{ }^{14} \mathrm{C}\right]$ inulin $(2.5 \mathrm{mCi} / \mathrm{g})$ and $\left[{ }^{3} \mathrm{H}\right]$ water $(1 \mathrm{mCi} / \mathrm{g})$ were purchased from Perkin-Elmer Life Sciences Inc. (Boston, MA, USA). All other reagents, unless otherwise noted, were purchased from Sigma Chemical Co. or Wako Pure Chemical Industries Co. (Osaka, Japan).

\section{Isolation of epididymal spermatozoa from mice}

Epididymal spermatozoa were isolated from 10-week-old male ddY mice. Whole epididymides were usually dissected out and minced into small fragments on ice in minimum essential medium (Gibco BRL). When regional differences were examined, epididymides were divided into three regions (caput, corpus, and cauda). These fragments were allowed to settle at $37^{\circ} \mathrm{C}$ for $5 \mathrm{~min}$, then the supernatant, containing spermatozoa that had swum up, was collected. The collected supernatant was centrifuged $(450 \mathrm{~g} \times 5 \mathrm{~min})$. The resultant pellet was washed twice with $\mathrm{PBS}$ and suspended in transport buffer $(125 \mathrm{mM} \mathrm{NaCl}, 4.8 \mathrm{mM} \mathrm{KCl}, 5.6 \mathrm{mM}$ (+)-glucose, $1.2 \mathrm{mM} \mathrm{CaCl} 2,1.2 \mathrm{mM} \mathrm{KH_{2 }} \mathrm{PO}_{4}, 1.2 \mathrm{mM} \mathrm{MgSO}_{4}, 25 \mathrm{mM}$ HEPES ( $\mathrm{pH}$ 7.4)). Isolated spermatozoa were used for immunofluorescence analysis and transport studies.

\section{Carnitine transport experiments}

Spermatozoa suspended in transport medium were stored on ice until transport experiments and were used within $3 \mathrm{~h}$ of preparation. HEK293 cells expressing mouse OCTN2 or OCTN3 were obtained by transfection of the parental cells with mouse OCTN2/pcDNA3 or mouse OCTN3/pcDNA3 vector respectively (Tamai et al. 2000).

The uptake of $\left[{ }^{3} \mathrm{H}\right]$ carnitine and $\left[{ }^{3} \mathrm{H}\right]$ acetylcarnitine by OCTN2- or OCTN3-expressing HEK293 cells or murine spermatozoa was examined by the silicon-layer method, as described previously (Tamai et al. 2000). The cellular protein content was determined according to the method of Bradford using a protein assay kit (Bio-Rad Laboratories) with BSA as the standard (Bradford 1976). In sodium-free experiments, sodium ions were usually replaced with $\mathrm{N}$-methylglucamine, and the cells obtained were suspended in sodium-free transport medium. 


\section{Data analysis}

The initial uptake rates were usually obtained by measuring the uptake over 3 min for carnitine and acetylcarnitine. The uptake values were usually expressed as the uptake clearance $(\mu \mathrm{L} / \mathrm{mg}$ protein/3 min), obtained by dividing the uptake amount in the cells by the concentration of test compound in the medium. $\left[{ }^{3} \mathrm{H}\right]$ Carnitine or $\left[{ }^{3} \mathrm{H}\right]$ acetylcarnitine uptake was usually obtained after correction for the extracellularly adsorbed amount, which was estimated from the uptake of $\left[{ }^{3} \mathrm{H}\right]$ carnitine or $\left[{ }^{3} \mathrm{H}\right]$ acetylcarnitine within a short time (about $5 \mathrm{~s}$ ) at $4{ }^{\circ} \mathrm{C}$. Intracellular water space in epdidymal spermatozoa was estimated as the difference between the uptakes of $\left[{ }^{3} \mathrm{H}\right]$ water and $\left[{ }^{14} \mathrm{C}\right]$ inulin.

To estimate the kinetic parameters for saturable transport of carnitine or acetylcarnitine, the uptake rate was fitted to the following equation by means of nonlinear regression analysis using the MULTI program (Yamaoka et al. 1981):

$$
V=V_{\max } \cdot C /(K m+C)+k d \cdot C,
$$

where $V$ and $C$ are the uptake rate and concentration of carnitine or acetylcarnitine respectively, and $K_{\mathrm{m}}, V_{\max }$, and $k_{\mathrm{d}}$ are the half-saturation concentration (Michaelis constant), the maximum transport rate, and the first-order rate constant for non-saturable transport respectively.

The $50 \%$ inhibitory concentration $\left(\mathrm{IC}_{50}\right)$ values of various inhibitors for $\left[{ }^{3} \mathrm{H}\right]$ acetylcarnitine uptake were estimated using the MULTI program according to the following equation:

$$
V=V_{0} /\left(1+\left(I / I C_{50}\right)\right)
$$

where $V$ and $V_{0}$ are the uptake rates of $\left[{ }^{3} \mathrm{H}\right]$ acetylcarnitine in the presence and the absence of inhibitor respectively, and $I$ is the concentration of inhibitor.

All results for the uptake rates were expressed as mean \pm s.E.M. and statistical analysis was performed by ANOVA with Tukey-Kramer's post hoc test. The criterion of significance was taken to be $P<0.05$.

\section{Immunofluorescence analysis of OCTN1, OCTN2, and OCTN3 in epididymal spermatozoa of mice}

Rabbit polyclonal antibodies for mouse OCTN1, OCTN2, and OCTN3 were prepared as described previously (Tamai et al. 2000). Immunofluorescence analysis was done according to our previous reports (Tamai et al. 2001, 2004, Wakayama et al. 2003). Briefly, isolated spermatozoa were fixed on glass slides and incubated with affinity-purified anti-OCTN antibodies or rabbit normal IgG. Then, they were incubated with Alexa Fluor 594 goat anti-rabbit IgG conjugate (Molecular Probes Inc., Eugene, OR, USA). Finally, they were mounted in VECTASHIELD mounting medium with DAPI (Vector Laboratories, Burlingame, CA, USA) to fix the sample and stain the nuclei. The specimens were examined with an Axiovert S 100 microscope (Carl Zeiss, Jena, Germany) and the images were captured with an AxioCam (Carl Zeiss). OCTN3-postive spermatozoa and head (nuclei) of spermatozoa were counted in a microscope and the ratio of OCTN3-postive spermatozoa (OCTN3-positive cells/head) was determined.

\section{Acknowledgements}

This study was supported in a part by a Grant-in-aid for Scientific Research from the Ministry Education, Culture, Sport, Science and Technology, Japan. The authors declare that there is no conflict of interest that would prejudice the impartiality of this scientific work.

\section{References}

Angulo C, Rauch MC, Droppelmann A, Reyes AM, Slebe JC, DelgadoLopez F, Guaiquil VH, Vera JC \& Concha II 1998 Hexose transporter expression and function in mammalian spermatozoa: cellular localization. Journal of Cellular Biochemistry 71 189-203.

Bradford MM 1976 A rapid and sensitive method for the quantitation of microgram quantities of protein utilizing the principle of protein-dye binding. Analytical Biochemistry 72 248-254.

Casillas ER 1972 The distribution of carnitine in male reproductive tissues and its effect on palmitate oxidation by spermatozoal particles. Biochimica et Biophysica Acta 280 545-551.

Casillas ER 1973 Accumulation of carnitine by bovine spermatozoa during maturation in the epididymis. Journal of Biological Chemistry $\mathbf{2 4 8}$ 8227-8232.

Casillas ER \& Chaipayungpan S 1979 The distribution of carnitine and acetylcarnitine in the rabbit epididymis and the carnitine content of rabbit spermatozoa during maturation. Journal of Reproduction and Fertility 56 439-444.

Casillas ER, Villalobos P \& Gonzales R 1984 Distribution of carnitine and acetylcarnitine in the hamster epididymis and in epididymal spermatozoa during maturation. Journal of Reproduction and Fertility 72 197-201.

Cooper TG, Gudermann TW \& Yeung CH 1986 Characteristics of the transport of carnitine into the cauda epididymidis of the rat as ascertained by luminal perfusion in vitro. International Journal of Andrology $\mathbf{9}$ 348-358.

Dacheux JL \& Paquingnon M 1980 Relations between the fertilizing ability, motility and metabolism of epididymal spermatozoa. Reproduction, Nutrition, Development 20 1085-1099.

Deana R, Rigoni F, Francesconi M, Cavallini L, Arslan P \& Siliprandi N 1989 Effect of L-carnitine and L-aminocarnitine on calcium transport, motility, and enzyme release from ejaculated bovine spermatozoa. Biology of Reproduction 41 949-955.

Enomoto A, Wempe MF, Tsuchida H, Shin HJ, Cha SH, Anzai N, Goto A, Sakamoto A, Niwa T, Kanai Y et al. 2002 Molecular identification of a novel carnitine transporter specific to human testis. Journal of Biological Chemistry 277 36262-36271.

Grundemann D, Harlfinger S, Golz S, Geerts A, Lazar A, Berkels R, Jung N, Rubbert A \& Schomig E 2005 Discovery of the ergothioneine transporter. PNAS 102 5256-5261.

Hinton BT, Snoswell AM \& Setchell BP 1979 The concentration of carnitine in the luminal fluid of the testis and epididymis of the rat and some other mammals. Journal of Reproduction and Fertility 56 105-111.

Hinton BT, Brooks DE, Dott HM \& Setchell BP 1981 Effects of carnitine and some related compounds on the motility of rat spermatozoa from the caput epididymidis. Journal of Reproduction and Fertility 61 59-64.

Jenkins AD, Lechene CP \& Howards SS 1980 Concentrations of seven elements in the intraluminal fluids of the rat seminiferous tubules, rete testis, and epididymis. Biology of Reproduction 23 981-987.

Jeulin C \& Lewin LM 1996 Role of free L-carnitine and acetyl-L-carnitine in post-gonadal maturation of mammalian spermatozoa. Human Reproduction Update 2 87-102.

Jeulin C, Soufir JC, Marson J, Paquignon M \& Dacheux JL 1987 The distribution of carnitine and acetylcarnitine in the epididymis and epididymal spermatozoa of the boar. Journal of Reproduction and Fertility 79 523-529.

Jeulin C, Dacheux JL \& Soufir JC 1994 Uptake and release of free L-carnitine by boar epididymal spermatozoa in vitro and subsequent acetylation rate. Journal of Reproduction and Fertility 100 263-271.

Johansen L \& Bohmer T 1979 Motility related to the presence of carnitine/acetylcarnitine in human spermatozoa. International Journal of Andrology 2 202-210. 
Kobayashi D, Irokawa M, Maeda T, Tsuji A \& Tamai I 2005 Carnitine/organic cation transporter OCTN2-mediated transport of carnitine in primarycultured epididymal epithelial cells. Reproduction 130 931-937.

Levine N \& Marsh DJ 1971 Micropuncture studies of the electrolyte transport in individual seminiferous tubules, the epididymis and the vas deferens in rats. Journal of Physiology 213 557-570.

Marquis NR \& Fritz IB 1965 Effects of testosterone on the distribution of carnitine, acetyl carnitine and carnitine acetyltransferase in tissues of the reproductive system of the male rat. Journal of Biological Chemistry $\mathbf{2 4 0}$ 2197-2200.

Nakanishi T, Hatanaka T, Huang W, Prasad PD, Leibach FH, Ganapathy ME \& Ganapathy V $2001 \mathrm{Na}^{+}$- and $\mathrm{Cl}^{-}$-coupled active transport of carnitine by the amino acid transporter $\mathrm{ATB}^{0,+}$ from mouse colon expressed in HRPE cells and Xenopus oocytes. Journal of Physiology 532 297-304.

Nezu J, Tamai I, Oku A, Ohashi R, Yabuuchi H, Hashimoto N et al. 1999 Primary systemic carnitine deficiency is caused by mutations in a gene encoding sodium ion-dependent carnitine transporter. Nature Genetics 21 91-94.

Ohashi R, Tamai I, Yabuuchi H, Nezu J, Oku A, Sai Y, Shimane M \& Tsuji A $1999 \mathrm{Na}^{+}$-dependent carnitine transport by organic cation transporter (OCTN2): its pharmacological and toxicological relevance. Journal of Pharmacology and Experimental Therapeutics 291 778-784.

Radigue C, Es-Slami S \& Soufir JC 1996 Relationship of carnitine transport across the epididymis to blood carnitine and androgens in rats. Archives of Andrology 37 27-31.

Sekine T, Kusuhara H, Utsunomiya-Tate N, Tsuda M, Sugiyama Y, Kanai Y \& Endou H 1998 Molecular cloning and characterization of high-affinity carnitine transporter from rat intestine. Biochemical and Biophysical Research Communications 251 586-591.

Soler C, Yeung CH \& Cooper TG 1994 Development of sperm motility patterns in the murine epididymis. International Journal of Andrology 17 $271-278$.

Tamai I, Yabuuchi H, Nezu J, Sai Y, Oku A, Shimane M \& Tsuji A 1997 Cloning and characterization of a novel human $\mathrm{pH}$-dependent organic cation transporter. FEBS Letters 419 107-111.

Tamai I, Ohashi R, Nezu J, Yabuuchi H, Oku A, Shimane M, Sai Y \& Tsuji A 1998 Molecular and functional identification of sodium ion-dependent, high affinity human carnitine transporter OCTN2. Journal of Biological Chemistry 273 20378-20382.

Tamai I, Ohashi R, Nezu J, Sai Y, Kobayashi D, Oku A, Shimane M \& Tsuji A 2000 Molecular and functional characterization of organic cation/carnitine transporter family in mice. Journal of Biological Chemistry 275 40064-40072.

Tamai I, China K, Sai Y, Kobayashi D, Nezu J, Kawahara E \& Tsuji A 2001 $\mathrm{Na}^{+}$-coupled transport of L-carnitine via high-affinity carnitine transporter OCTN2 and its subcellular localization in kidney. Biochimica et Biophysica Acta 1512 273-284.
Tamai I, Nakanishi T, Kobayashi D, China K, Kosugi Y, Nezu J, Sai Y \& Tsuji A 2004 Functional characterization and renal apical membrane localization of organic cation transporter OCTN1 (SLC22A4). Molecular Pharmaceutics 1 57-66.

Toshimori K, Kuwajima M, Yoshinaga K, Wakayama T \& Shima K 1999 Dysfunctions of epididymis as a result of primary carnitine deficiency in juvenile visceral steatosis mice. FEBS Letters 446 323-326.

Turner TT, Hartmann PK \& Howards SS 1977 In vivo sodium, and sperm concentrations in the rat epididymis. Fertility and Sterility $\mathbf{2 8}$ 191-194.

Wakayama T, Koami H, Ariga H, Kobayashi D, Sai Y, Tsuji A, Yamamoto M \& Iseki S 2003 Expression and functional characterization of the adhesion molecule spermatogenic immunoglobulin superfamily in the mouse testis. Biology of Reproduction 68 1755-1763.

Wu X, Prasad PD, Leibach FH \& Ganapathy V 1998 cDNA sequence, transport function, and genomic organization of human OCTN2, a new member of the organic cation transporter family. Biochemical and Biophysical Research Communications 246 589-595.

Wu X, Huang W, Prasad PD, Seth P, Rajan DP, Leibach FH, Chen J, Conway SJ \& Ganapathy V 1999 Functional characteristics and tissue distribution pattern of organic cation transporter 2 (OCTN2), an organic cation/carnitine transporter. Journal of Pharmacology and Experimental Therapeutics 290 1482-1492.

Wu X, George RL, Huang W, Wang H, Conway SJ, Leibach FH \& Ganapathy V 2000 Structural and functional characteristics and tissue distribution pattern of rat OCTN1, an organic cation transporter, cloned from placenta. Biochimica et Biophysica Acta 1466 315-327.

Xuan W, Lamhonwah AM, Librach C, Jarvi K \& Tein I 2003 Characterization of organic cation/carnitine transporter family in human sperm. Biochemical and Biophysical Research Communications 306 121-128.

Yabuuchi H, Tamai I, Nezu J, Sakamoto K, Oku A, Shimane M, Sai Y \& Tsuji A 1999 Novel membrane transporter OCTN1 mediates multispecific, bidirectional, and $\mathrm{pH}$-dependent transport of organic cations. Journal of Pharmacology and Experimental Therapeutics 289 768-773.

Yamaoka K, Tanigawara Y, Nakagawa T \& Uno T 1981 A pharmacokinetic analysis program (MULTI) for microcomputer. Journal of PharmacobioDynamics 4 879-885.

Yeung CH, Cooper TG \& Waites GMH 1980 Carnitine transport into the perfused epididymis of the rat: regional differences, stereospecificity, stimulation by choline, and the effect of other luminal factors. Biology of Reproduction 23 294-304.

Received 29 August 2006

First decision 27 September 2006

Revised manuscript received 8 July 2007

Accepted 7 August 2007 